\title{
Investigation and Visualization of Shock Induced Strain in Olivine using In Situ Micro-X-Ray Diffraction and Electron Backscatter Diffraction
}

\author{
YAOZHU LI, PHIL J. A. MCCAUSLAND AND ROBERTA L. \\ FLEMMING \\ Western University
}

Presenting Author: yli2889@uwo.ca

Shock metamorphism is a common deformation type in the solar system but is rare on Earth. Peak shock pressure can be as high as $60 \mathrm{GPa}$, releasing enormous energy instantaneously. Olivine in geological settings experience a slow strain rate ( $\sim 10^{-15} / \mathrm{s}$ ), e.g., tectonism, developing lattice preferred orientation as a result of migration of dislocation creep, whereas olivine in shocked meteorites experienced an extreme strain rate $\left(10^{6} / \mathrm{s}\right)$ resulting from the instantaneously released shock energy. Shock effects are deconstructive, inducing non-uniformly distributed strain in the olivine crystal, developing a series of deformation textures in optical petrography such as planar fractures, undulatory extinction, and mosaicity. Post-shock effects may cause further dislocation migration resolving strains by recrystallization. In this study, we present our work on shocked meteorites and compare with terrestrial samples to investigate the strains that are created by shock and stored in olivine crystal lattices. We use in situ micro-X-ray diffraction to examine shocked olivine in ureilites, a type of ultramafic achondrite, and a chassignite, representing martian cumulate dunite. We find that shocked olivine displays a range of 2D XRD patterns, from spots (slightly shocked single grain), to streaks, or mosaic spread along Debye Rings, and asterism (large visible subdomains on thin sections). We further use Electron Backscatter Diffraction to investigate subdomain misorientation in large olivine grains in martian dunite sample Northwest Africa NWA 2737 (moderate to high shock) applying Weighted Burger Vector techniques, a mathematical method developed by Wheeler et al. (2009) ${ }^{[1]}$ coded with MTex in Matlab. We report that subdomain boundaries are dominated by titled walls $(\sim 80 \%)$ indicating the edge dislocation is the primary type (misorientation axis is perpendicular to Burger vectors). The predominant slip systems are not as obvious as what has been observed in the terrestrial samples. For localized preferred orientation in NWA 2737, the slip direction is dominated by the a- axis [100] slip. The misorientation axes form a large angle $\left(>70^{\circ}\right)$ with the crystallographic axes a-[100] and b-[010] and a small angle $\left(<20^{\circ}\right)$ to the $\mathrm{c}$-[001]. We will compare this result to nonshocked mantle xenocrysts in kimberlites.

[1] Wheeler et al. (2009), J. of Microscopy, 233(3), 482-494 